\title{
LA DIMENSIÓN MATERIAL DE UN PUEBLO DE INDIOS: LA ESTANCIA DE GUACO A TRAVÉS DE FUENTES JUDICIALES (LA RIOJA, 1685)
}

\author{
THE MATERIAL DIMENSION OF A COLONIAL INDIAN VILLAGE: \\ GUACO'S RANCH THROUGH JUDICIAL DOCUMENTS \\ (LA RIOJA, 1685)
}

\author{
Marisol García*
}

\begin{abstract}
El objetivo de este trabajo es describir el ordenamiento espacial de un pueblo de indios del siglo XVII. La estancia de Guaco, ubicada en La Rioja (gobernación del Tucumán, virreinato del Perú), funcionó como lugar de reducción de la encomienda de malfín, andalgalá y "anexos" durante parte del siglo XVII. Se identificarán los distintos espacios que lo conformaron y se confrontará la organización material de este pueblo con la normativa reduccional alfariana, con el fin de evaluar la eficacia de este dispositivo colonial en el disciplinamiento de la población indígena. La base documental de esta investigación es una fuente inédita de 1685, denominada "evaluación y tasación de mejoras y daños que se hallaren en el Pueblo de Guaco". La misma forma parte de un expediente judicial del Archivo y Bibliotecas Nacionales de Bolivia donde distintos actores se disputan el usufructo y propiedad de las tierras de Guaco. La organización espacial develada servirá para realizar futuras comparaciones con otros pueblos o reducciones coloniales que pudieran analizarse. Además, el artículo aporta al debate de los pueblos indígenas desnaturalizados, evidenciando las consecuencias del proceso de desnaturalizaciones desde el caso de los malfines y andalgalás.
\end{abstract}

Palabras claves: Pueblo de indios, ordenamiento espacial, fuentes judiciales, ordenanzas de Alfaro.

The aim of this paper is to describe the spatial order of an Indian village located in jurisdiction of La Rioja (Tucuman Province, Viceroyalty of Peru) in the seventeenth century. The 'Guaco' ranch was the place where the indigenous groups of Malfin and Andalgala were settled. In this work, the different spaces that conform the village will be identified. Then, I will confront the organization of this town with the colonial regulations made by Alfaro. The purpose is to evaluate the effectiveness of this colonial device in the discipline of the indigenous population. This investigation is based on an unpublished judicial document of 1685, called "evaluation and valuation of the improvements and damages found in the Village of Guaco". It is part of a judicial lawsuit where residents of La Rioja, encomenderos and indigenous dispute the usufruct and ownership of the lands of Guaco. The spatial organization that is revealed in this article will serve to make future comparisons with other Indian villages. Furthermore, this study shows the consequences of the desnaturalizaciones from the case of the Malfines and Andalgalás.

Key words: Indian Village, spacial description, judicial documents, Alfaro's ordinances.

\section{Los pueblos de indios de la gobernación del Tucumán: breve revisión historiográfica}

La política de reducir a las poblaciones nativas y sujetarlas a un territorio nace junto con la conquista de América, pero es a partir del gobierno del virrey Toledo (1572) que la misma comenzó a ser aplicada sistemáticamente en los reinos de Perú y el área andina (Mumford 2012; Wernke 2013). Los españoles concibieron la reducción, es decir, el agrupamiento territorial de la población indígena en un espacio fijado, como la manera más eficiente de dominar a los indígenas, catequizarlos y recaudar los tributos (Gade 1991: 71).
Con estos objetivos se crearon los pueblos de indios o reducciones, que, sobre un diseño urbano en damero reunían a la población dispersa de los ayllus y comunidades. Recordemos que los modos de asentamientos andinos, caracterizados por formas salpicadas, discontinuas e interdigitadas de habitar el territorio y por una concepción del espacio no solo física sino también sagrada y política, tensionaban y contrastaban con la compacta, delimitada y continua territorialidad castellana (Zagalsky 2009: 60).

Para la gobernación del Tucumán fue el oidor Francisco de Alfaro quien buscó implementar el sistema de reducciones o pueblos de indios desde

* Instituto de Historia Argentina y Americana “Dr. E. Ravignani”, Facultad de Filosofía y Letras, Universidad de Buenos AiresConsejo de Investigaciones Científicas y Técnicas. Buenos Aires, Argentina. Correo electrónico: msolgarcia737@gmail.com 
1612, especificando cómo debían organizarse y otorgando tierras a los indígenas. Se entiende que:

El pueblo de indios era una unidad social, territorial y jurisdiccional que, en el caso de la antigua Gobernación del Tucumán, tenía su inspiración en las reducciones toledanas y suponía tres características distintivas: un régimen particular de usufructo en común de las tierras asignadas a cada pueblo, cuyo dominio eminente retenía la Corona y se mantenían fuera del mercado; un conjunto de autoridades compuesto por cacique y cabildo indígena; y la obligación de los sujetos de responder a una carga tributaria por su condición de indio originario (Tell y Castro Olañeta 2016: 211).

Tierra comunitaria, autoridades indígenas y un sistema de tributación son según las autoras los elementos centrales de los pueblos de indios. Excede los objetivos de este trabajo determinar el grado de alcance y la aplicabilidad de la normativa que reglaba la conformación de los pueblos de indios. No obstante, es sabido que la creación de las reducciones suscitó notorias resistencias entre los encomenderos del Tucumán, reacios a perder el poder que habían construido en el vínculo con sus encomendados (Palomeque 2000).

Las investigaciones respecto de los pueblos de indios de la gobernación del Tucumán priorizaron ciertas dimensiones y aspectos de los mismos. Para empezar, hay estudios que se enfocaron en la dimensión económica, entendiendo al pueblo como una unidad productiva dentro del sistema colonial. Por ejemplo, Boixadós (2002) analiza las formas de tributación existentes en los pueblos de indios riojanos en 1693, mientras que Castro Olañeta (2006) estudia el sistema de producción y explotación económica en el pueblo de indios de Quilino (Córdoba) a principios del siglo XVII. El reciente trabajo de Conti (2019) aborda las encomiendas catamarqueñas, comparando las formas de explotación del trabajo indígena -principalmente el "servicio personal" - en aquellas asentadas en pueblos de indios y las asentadas en tierras privadas.

Asimismo, otros investigadores estudiaron la dimensión política, relacionada con el rol de las autoridades étnicas y el funcionamiento del cabildo indígena. Es el caso de Sica (2009) y de la Orden de Peracca (2011), quienes examinan las transformaciones de los liderazgos étnicos en San Salvador de Jujuy y Catamarca, respectivamente, a partir de la creación y puesta en funcionamiento de los cabildos indígenas, los que suponían la incorporación de otras autoridades como los alcaldes y regidores.

Asimismo, numerosos trabajos focalizaron en la dimensión sociodemográfica, asociada al mestizaje cultural y biológico que ocurría en estos espacios y a los movimientos poblacionales. El trabajo de Anello (2002) acerca de los pueblos de Colpes, Sijan y Sabuil en Catamarca analiza la estructura de los hogares y la incidencia de los procesos de desestructuración (la migración forzada, las exigencias económicas, la evangelización, etc.). Otros estudios de estas características se encuentran en el libro Los pueblos de indios en Catamarca Colonial, editado por la Orden de Peracca (2008).

También se ha indagado pertinente a la dimensión simbólica. Por un lado podemos mencionar a los trabajos que entienden a los pueblos de indios como una forma de plasmar y territorializar el dominio colonial. Tell y Castro Olañeta entienden a los pueblos de indios como un símbolo del "pacto colonial o de reciprocidad" que mantuvieron los indígenas con la Corona española, pagando el tributo a cambio de recibir el usufructo de tierras comunales (2016: 211). Para Giudicelli, la formación de los pueblos de indios responde al proyecto de disciplinar a la población indígena rebelde, relocalizándola en espacios ya disciplinados fuera de su lugar natural y donde se instalarán estructuras de producción coloniales (2018: 141).

A su vez están los estudios que abordan a los pueblos de indios como factores de identidad. Sica (2008) analiza los modos de construcción de identidades locales centradas en los pueblos de indios de Jujuy durante el siglo XVII, examinando la activa participación de los caciques y otras autoridades de los pueblos en la protección del espacio y la supervivencia de las comunidades. En esta misma línea se ubica el trabajo de Vázquez concerniente a los Tinogasta en Belén (2007). El autor observa que el reclamo jurídico de las tierras donde fueron asentados, apelando a la posesión desde "tiempos inmemoriales", es el marco de referencia desde donde la parcialidad Tinogasta en Belén construye su propio pasado e identidad (Vázquez 2007: 14).

Además, existen nutridas investigaciones de cómo se realizó la política de reducciones indígenas en la gobernación, cuáles fueron sus características según la región y época, qué condiciones posibilitaron 
su pervivencia o su destrucción, entre otros aspectos. No puedo dejar de mencionar los trabajos señeros de Lorandi (1988), quien enfatizó el veloz proceso de desestructuración socioeconómica e identitaria que atravesaron muchas comunidades y pueblos de indios al estar en manos de encomenderos abusivos, y de Palomeque (2000), quien reconstruye la historia de las sociedades indígenas sometidas por el sistema colonial en la gobernación del Tucumán. A su vez, Farberman y Boixadós (2009-2010) analizan las transformaciones que transitaron los pueblos de indios del Tucumán de manera comparativa en las distintas jurisdicciones de la gobernación. El ya mencionado trabajo de Tell y Castro Olañeta (2016) hace un seguimiento de los pueblos de indios de Córdoba, mientras que el de Farberman (2008) con los de Santiago del Estero.

Resumiendo, en este apartado vimos que los pueblos de indios de la gobernación del Tucumán han sido ampliamente estudiados por la historiografía, aunque las investigaciones priorizaron ciertas dimensiones, destacando la económica, la política, la sociodemográfica y la simbólica. La dimensión material y espacial de los pueblos de indios, entendida como el proceso de producción social del espacio ${ }^{1}$, no ha sido una problemática demasiado explorada, salvo por trabajos puntuales interdisciplinarios vinculados a la arqueología (Taboada y Farberman 2014). El presente trabajo profundizará esta dimensión, utilizando además fuentes novedosas para abordar la temática como los pleitos judiciales.

Se espera que la organización espacial develada en este artículo sirva para realizar futuras comparaciones con otros pueblos de indios que se pudieran analizar. Adicionalmente, el estudio permite profundizar en las consecuencias y derivaciones del proceso de las desnaturalizaciones calchaquíes acontecidas luego del quiebre de la resistencia armada de las poblaciones indígenas rebeldes o "alzadas". En este caso se indaga en la historia de poblaciones malfines y andalgalás asentadas en la estancia de Guaco a partir de su incorporación en una misma encomienda.

\section{La organización espacial de los pueblos de indios: el ordenamiento alfariano y su aplicación en La Rioja}

El licenciado Francisco de Alfaro, oidor de la Audiencia de Charcas, fue quien reglamentó la disposición de los pueblos de indios para la gobernación del Tucumán ${ }^{2}$. Primer visitador y funcionario "externo" a la gobernación, llegó luego de un extenso proceso de denuncias y solicitudes por parte de distintos sectores de la sociedad colonial local pidiendo una visita general (Palomeque 2000; Tell y Olañeta 2016: 211). Durante 1611 Alfaro visitó personalmente los indios encomendados en las distintas jurisdicciones de la gobernación, asignándoles tierras comunitarias a aquellos grupos que no las poseían. Aunque los autos de la visita todavía no se encontraron, sí están disponibles sus ordenanzas de 1612. Las mismas estuvieron inspiradas en el modelo toledano, especialmente en lo tocante a la relación entre la reducción en pueblos y el reconocimiento legal de las tierras, el pago de tributo y la entrega de mita. En este apartado mencionaré las ordenanzas que atañen a la dimensión material de los pueblos de indios.

Las primeras ordenanzas que refieren a las reducciones están vinculadas a la prohibición de mudar a los indios del lugar donde fueron asentados (número cinco). Al respecto, la ordenanza ocho dice que no se podrá trasladar a los indígenas "de un temple a otro" y que cerca de las reducciones tiene que haber una fuente de agua (río, estero, bañado, laguna o pantano). Profundizando en el primer aspecto, la ordenanza nueve manda que los indígenas no se muden contra su voluntad, ya que son los que más saben de la tierra y sus cualidades (Leviller 1918). En estas normas se distingue la voluntad del visitador de que las reducciones fueran hechas en las tierras propias de los indios, separadas de las tierras de españoles, de acuerdo con el temple y teniendo en cuenta que pudieran acceder a varios recursos fundamentales como agua y leña y posibilidades de hacer sementeras. Es importante remarcar que el visitador consideró valiosa la opinión de los indígenas respecto de qué lugar era el más adecuado para vivir.

La ordenanza $\mathrm{N}^{\circ} 20$ indica que:

en cada pueblo o reducción de indios por pequeño que sea aya de aver y aya una iglesia o capilla donde con decencia se celebre y pueda decir misa y aya de tener y tenga puerta con llave para que no se profanen ni entren animales en ella (Leviller 1918: 301).

Otra ordenanza importante para el ordenamiento material de las reducciones es la $\mathrm{N}^{\mathrm{o}} 26$, donde 
establece que el encomendero no puede tener casa ni propiedades a su nombre en el pueblo, pero sí puede haber

cassa de telares para que los indios trabaxen y bodega o despensa donde al yndio a quien se encargare tenga los especies beneficiados o por beneficiar que son para los tributos [...] y ansi mismo aya dos aposentos para tambo o pasada de la justicia que pudiere y deviere vissitarlos sin que de cosa alguna dello el dicho comendero ni otro por el pueda tener llave pero permitese que en el pueblo pueda el encomendero tener casa de trigo para encerrar el trigo cebada maíz o algarrobas o otra comida que tubiere la qual tenga la puerta cerrado con barro o si fuere con llave que tenga la llave en la ciudad su amo o un yndio en el pueblo que escogiere (Leviller 1918: 303-304).

Siguiendo la misma línea, la ordenanza $\mathrm{N}^{\circ} 27$ prohíbe los obrajes o viñas del encomendero, diciendo que solo puede tener chacras de comida, algunos árboles frutales y ganado. La ordenanza $\mathrm{N}^{\circ} 33$ establece que no puede haber chacras de los españoles a menos de media legua de los contornos de los pueblos existentes (en 1612), o a una legua de los futuros pueblos de indios. De esta forma deja bien en claro que el territorio indígena debe estar separado del de otros actores. Las siguientes ordenanzas versan en torno a la distancia que se tiene que encontrar el ganado -de los indígenas y de otras estancias- de las chacras de los indios, para que el mismo no arruine los cultivos ( $\left.\mathrm{N}^{\circ} 34\right)$. Se plantea que en los pueblos debe haber un ejido de media legua más o menos dependiendo la cantidad de indios, donde tengan sus ganados separados de los de españoles. Si el pueblo no tuviere pasto, el ejido será lo más cercano posible $\left(\mathrm{N}^{\mathrm{o}} 35\right)$.

No obstante la uniformidad del sistema legal, las variaciones regionales en la aplicación de este modelo fueron significativas. Farberman y Boixadós analizan comparativamente la situación de los pueblos de indios en distintas jurisdicciones (2009-2010). Teniendo en cuenta la incidencia de las desnaturalizaciones y la disponibilidad o no de tierras comunitarias distinguen tres situaciones. En Jujuy y Santiago del Estero observan la existencia y el funcionamiento de pueblos de indios y con ellos el acceso a tierras propias. En el polo opuesto, Córdoba y Catamarca no registran casi pueblos de indios formalmente constituidos, estando prácticamente todos los tributarios alojados en las estancias de sus encomenderos. La Rioja, San Miguel de Tucumán y Salta constituyen casos intermedios (2009-2010). Debido al caso de estudio aquí abordado, la situación de La Rioja es la que reviste mayor interés.

Como en otras partes de la gobernación, en La Rioja los encomenderos resistieron la abolición del servicio personal, dilatando la aplicación de las ordenanzas. Según Farberman y Boixadós bien pudo ser esta la causa de la gran rebelión diaguita que se desato años después (1630-1643) (2006: 607). La pacificación posterior y las desnaturalizaciones acabaron creando las condiciones con las que las reducciones y el nuevo régimen de tributación serían paulatinamente impuestos desde la segunda mitad del siglo XVII.

Boixadós (2002) demuestra que a fines del siglo XVII en La Rioja coexistían principalmente dos escenarios. Por un lado, había encomiendas radicadas en pueblos con tierras comunales, compuestas por población diaguita local y algunas etnias desnaturalizadas. La autora utiliza el término de "encomiendas pueblo" para dar cuenta de la situación de algunos de estos grupos en los que la condición de encomienda y pueblo de indios se superpone, muchas veces producto de las reducciones posteriores al gran alzamiento (2002: 31).

De manera opuesta, encuentra encomiendas asentadas en tierras de particulares, en las propiedades urbanas o semiurbanas de sus encomenderos. Estas estaban ostensiblemente en peores condiciones, ya que carecían de tierras comunitarias, base central para la reproducción autónoma del grupo. Los diaguitas-calchaquíes que habían sido desnaturalizados durante la última campaña (1659-1666) y los tobas y mocovíes provenientes del Chaco eran quienes se encontraban mayormente en tierras privadas (Boixadós 2002). Aunque el tributo (pagado en especies y en trabajo con equivalencia monetaria) dominaba en los pueblos, el servicio personal continuaba vigente, con mayor fuerza en los grupos más pequeños y desestructurados asentados en las casas de sus amos.

\section{Nuestro natural apacible: el pueblo de indios de Guaco}

La estancia de Guaco $^{3}$ (ubicada en el valle de Sanagasta, aproximadamente $30 \mathrm{~km}$ al norte de 
la ciudad de La Rioja) funcionó como el lugar de reducción de la encomienda de malfín, andalgalá y "anexos" desde la mitad del siglo XVII hasta el siglo siguiente. Las poblaciones que componían la encomienda fueron desnaturalizadas del oeste catamarqueño como represalia por su participación protagónica en el "Gran Alzamiento Diaguita" de $1630^{4}$. Fueron llevadas a La Rioja mediante traslados forzosos en distintas etapas. A medida que fueron llegando, su encomendero, don Isidro de Villafañe y Guzmán, las "asitió y asementó" en sus propiedades: en su chacra y cuadra en las afueras de la ciudad de La Rioja y en su estancia denominada "Guaco"5. En esta última, los indígenas construyeron una capilla, sus ranchos y sementeras, mientras que él explotaba la hacienda y viña como parte del circuito del vino (Lorandi y Sosa Miatello 1991: 14).

Luego de la visita general a las jurisdicciones de Londres y La Rioja ordenada por el gobernador Alonso de Mercado y Villacorta realizada en 1667 por el visitador Pedro Nicolás de Brizuela, se les otorgó tierras a los indígenas dentro de la estancia de Guaco. Así lo cuentan ellos en un interrogatorio en 1682:

dijeron que [...] lo que hay obrado de casa iglesia y troga lo han hecho ellos después de que el dicho gobernador don Alonso de Mercado los visitó [...] y entonces les dio la mitad de estas tierras y que en la otra mitad sembrase su amo y les señaló el sitio donde tienen la iglesia hecha y que lo demás que hay de acementos lo han hecho como en cosa suya (AHPC, Esc 2, Leg. 5, Exp. 11, Fol. 222 r.)

Según esta información ${ }^{6}$, en 1667 las tierras de Guaco se dividen: mitad queda en manos de su encomendero y propietario, Villafañe, y mitad para ellos en calidad de pueblo de indios o reducción, en tanto poseía los requisitos necesarios: tierras de comunidad señaladas, autoridades étnicas y comunidad de tributarios. Podemos pensar en Guaco como una encomienda-pueblo en términos de Boixadós (2002), ya que en las fuentes el término 'Guaco' a veces se utiliza para denominar a la encomienda y a sus miembros, otras veces alude a su organización como pueblo de indios o reducción y en ocasiones se refiere a la estancia perteneciente a la familia Villafañe.

Es importante mencionar que a pesar de las intenciones hispanas de localizar y anclar la población indígena a un espacio determinado, estos grupos siguieron manteniendo patrones de traslado y movilización por el territorio. Guaco, como otras estancias productivas de La Rioja, estaba dentro de los circuitos mercantiles de la gobernación del Tucumán y del virreinato del Perú. Los indígenas participaban de estos mercados para cumplir su tributo u obligaciones con el encomendero como para hacer negocios individuales o conciertos. Miembros de la encomienda se desempeñaban como arrieros y realizaban numerosos viajes en carreta, transportando distintos productos ${ }^{7}$.

Entonces, a pesar de tener su residencia oficial en Guaco, el habitual desplazamiento por el territorio los llevó a tener otros lugares de paraje. Las fuentes indican que no todos se encontraban en Guaco la última mitad del siglo XVII, algunos vivían en la casa del encomendero en la ciudad de La Rioja, otros servían a algunos vecinos riojanos y un tercer grupo se encontraba en la jurisdicción de Londres o en Córdoba (García 2018b). Esto evidencia la coexistencia y superposición de distintas territorialidades: una impuesta, que remite al modelo castellano, visible en el pueblo de reducción, junto con una territorialidad móvil acorde a la reproducción indio-campesina andina y con las propias necesidades de movilidad del sistema colonial.

Con la muerte de Villafañe en 1674, la encomienda sale de la órbita de la familia y se otorga en primera vida a otro vecino riojano: don Gil Gregorio Bazán de Pedraza. Esto va a generar graves inconvenientes que desembocan en un juicio ${ }^{8}:$ los herederos de Villafañe (los Vergara) quieren usufructuar la estancia de Guaco y, como la encomienda no les pertenece, recuperar las tierras que les fueron dadas a los indígenas. Por su parte, Bazán de Pedraza se niega a trasladarlos. En los litigios, no solo interviene el estamento encomendero, sino que las autoridades indígenas de Malfin y Andalgalá acuden a los juzgados y audiencias tratando de influir el resultado (ver García 2018a). Entre 1683 y 1684 los indígenas se trasladan a Andalgalá en Catamarca y toman posesión de la estancia los herederos de Villafañe. No obstante en 1685 los caciques don Jerónimo Pibala y don Pedro Aballay obtienen una Real Provisión para asentarse nuevamente en Guaco, después de haberlo descrito como su "natural apacible y cómodo". La Provisión dice:

Ampárese a los caciques y a todos los indios malfines y andalgalas trasplantados al sitio de Guaco jurisdicción de La Rioja 
en la posesión en que estaban al tiempo en que se introdujo este litigio con su pueblo, iglesia, ranchos, ganados mayores $\mathrm{y}$ menores aguas acequias tomas y pastos y todo lo demás que por razón de dicha situación habían gozado y poseído y en caso necesario se les restituye y reintegra y pon en el mismo estado en que entonces estaban (ABNB EC-1688,42 Fol. 22 r.).

Para dar cumplimiento a la Provisión, los Villafañe-Vergara son desalojados de Guaco, bajo la promesa de que el encomendero Bazán de Pedraza les pagaría el valor de las tierras. Después de expulsarlos, los indígenas toman la posesión efectiva de Guaco:

en el sitio y pueblo de Guaco en once días del mes de mayo de 1685 años el Capitán Don Alonso Moreno Gordillo juez comisionario de la Real Audiencia de La Plata para dar la posesión del dicho sitio y pueblo de Guaco a los caciques e indios de los pueblos de malfín y andalgalá encomienda del Capitán Don Gil Gregorio Bazán de Pedraza [...] en virtud de la Real Provisión mandé parecer a Don Pedro Aballay y Don Gerónimo Pibala caciques principales de dichos pueblos de malfín y andalgalas y a sus sujetos indios [...] con sus mujeres, hijos y demás familia a los cuales en presencia del Capitán Don Juan de Herrera y Guzmán alcalde ordinario y protector nombrado para esta causa y de dicho su encomendero y testigos que irán firmados los cogí uno por uno de la mano y en nombre de su Majestad que Dios guarde los metí y di posesión judicial, real, actual, jure domini vel quasi del dicho pueblo de Guaco su iglesia tierras y acequias con sus aguadas, toma, montes y pastos y lo demás de que ordena y manda la dicha Real Provisión $y$ en señal de ella y de haber aprehendido dicha posesión arrancaron hierbas, tiraron piedras y se pasearon por dichas tierras e hicieron otros actos de posesión diciendo a los circundantes se saliesen de sus tierras (ABNB EC-1688,42 Fol.25)

Luego de la toma de posesión de su pueblo de Guaco, el alcalde don Alonso Moreno Gordillo pide que ambas partes, los Vergara y los indios aconsejados por su protector, nombren tasadores. Estos debían evaluar el estado del pueblo, reparando en las mejoras y deterioros que se produjeron mientras las tierras fueron ocupadas por los Vergara, ya que la Provisión mandaba que los indígenas tomen posesión de Guaco "en el mismo estado que estaba" antes. Los Vergara se niegan a elegir un tasador y piden que lo elija la justicia, lo que realiza rápidamente Gordillo. El alcalde nombra dos tasadores de oficio, "dos personas de ciencia y consciencia": don José Sánchez de Loria en representación de los Vergara y don Juan Gregorio Bazán de Pedraza en representación de los indígenas 9 .

Entre el 12 y 14 de mayo de 1685 se realiza el reconocimiento. En este documento Gordillo describe con detalle gran parte de las construcciones y espacios que había en Guaco, permitiéndome realizar una reconstrucción parcial del pueblo. En primer lugar se mencionan las mejoras que se encontraron en Guaco. Debido a la riqueza de las descripciones contenidas en la fuente, confeccioné una tabla donde se observan los comentarios de los tasadores acerca de cada uno de estos espacios.

Estos elementos que se describen como mejoras no llevan el nombre de ninguno de los habitantes del pueblo, por lo que interpreto que su uso (exceptuando quizás los aposentos de vivienda) era comunitario. $\mathrm{Si}$ reparamos en los precios asignados a cada uno de estos espacios por los tasadores, los de mayor valor son en primer lugar el perchel, depósito en donde se almacenaba la producción, luego la capilla con sus ornamentos e imágenes y en tercer lugar los elementos que componían el sistema de riego. En el documento se observa que la mayoría de las edificaciones de Guaco están construidas con pirca de adobes y barro y que los techos son de "barason y terrado como todos los demás edificios de este pueblo de Guaco que están cubiertos de torta de barro" (ABNB EC-1688,42 Fol. 31 r.).

Luego, continúa con la enunciación de los ranchos que fueron quemados y se consignan como un deterioro del pueblo. Estos, a diferencia de los espacios mencionados anteriormente, son asignados a distintos individuos y familias. Se registra que "fueron 22 los dichos ranchos que parecen haberse quemado y arruinado con más 6 buhíos y 12 ramadas de todo lo cual no se halló madera ni pared ni cerco de paja que pueda servir" (ABNB EC-1688,42 Fol. 28 r.). En la fuente se describe cada uno de estos espacios, su dueño y el valor que le otorgan. Cito como ejemplo algunos fragmentos: 
Tabla 1. Obras y mejoras del pueblo de Guaco/ Works and improvements in Guaco's Village

\begin{tabular}{|c|c|c|}
\hline Mejora & Descripción & Precio \\
\hline $\begin{array}{l}\text { Capilla con } \\
\text { ornamentos }\end{array}$ & $\begin{array}{l}\text { Es de pared de adobes contraminada de abejones toda la cumbre que } \\
\text { es de tijera corrida portada dos puertas de tabla, cerradura y llave, una } \\
\text { ventanilla }[\ldots] \text { en medio del altar vi un cajoncillo que dijeron ser nicho } \\
\text { una imagen de nuestra señora }\end{array}$ & 230 pesos y 4 reales \\
\hline $\begin{array}{l}\text { Docel y cielo de la } \\
\text { capilla }\end{array}$ & Viejos y la mesa del altar y 4 estampas de papel viejas todo de dicha capilla & 14 pesos \\
\hline Lienzo & Del señor San Isidro usado puesto en su bastidor & 20 pesos \\
\hline $\begin{array}{l}\text { Perchel o troja en que } \\
\text { se recogen las comidas }\end{array}$ & $\begin{array}{l}\text { De } 74 \text { pasos ordinarios de largo, armado sobre horcones de madera de } \\
\text { algarrobo y cumbreras de lo mismo con toda su barason y techumbre } \\
\text { puertas de tabla y su marco en una portada un pedazo de dicho perchel } \\
\text { el de embarrado y lo demás que muestra haberlo sido y esta arruinado }\end{array}$ & 287 pesos y 4 reales \\
\hline $\begin{array}{l}\text { Tres aposentos } \\
\text { pequeños de vivienda, } \\
\text { una cocina y dos } \\
\text { ramadas }\end{array}$ & $\begin{array}{l}\text { Armados sobre horcones pequeños con pirca del grueso de un adobe } \\
\text { maltratado de las aguas y abejones todas sus maderas y tres puertecillas la } \\
\text { una de tabla y dos de cuero de vaca en sus bastidores dichas pircas y techo }\end{array}$ & 52 pesos y 4 reales \\
\hline Cocina & $\begin{array}{l}\text { Armada sobre horconcillos con su pirca de adobes y su techo de barason y } \\
\text { terrado como todos los demás edificios de este pueblo de Guaco que están } \\
\text { cubiertos de torta de barro la dicha cocina y las maderas de otro rancho } \\
\text { arruinadas las pircas del que está pegado a ella y sin puertas }\end{array}$ & 30 pesos y 4 reales \\
\hline Caballeriza & $\begin{array}{l}\text { Arruinada sus cercas y pajas con media puerta desgobernada de reja }[\ldots] \\
\text { de palo y un umbral todo descompuesto y dos horcones y una cumbrera } \\
\text { puestos en ella }\end{array}$ & $\begin{array}{l}6 \text { pesos las dichas } \\
\text { maderas y el cerco de } \\
\text { dicha caballeriza por } \\
\text { arruinado no se le halló } \\
\text { precio }\end{array}$ \\
\hline Aposento de vivienda & Embarrado caída la mitad & 16 pesos \\
\hline La toma del agua & $\begin{array}{l}\text { Que corre a las tierras de labor con un pedazo de fábrica de cal y canto// } \\
\text { Y ten } 13 \text { varas de cal y canto que tiene una pared de la toma del agua de } \\
\text { este dicho pueblo que sale a las tierras regaderas }\end{array}$ & 34 pesos \\
\hline $\begin{array}{l}\text { Las acequias que } \\
\text { corren a dichas tierras }\end{array}$ & $\begin{array}{l}\text { La abertura y forma de las acequias corrientes a la vivienda al estanque y } \\
\text { tierras de labor en el estado que estan al presente medio siegas y sacadas } \\
\text { por tierra suelta }\end{array}$ & 33 pesos \\
\hline Un estanque o represa & $\begin{array}{l}\text { Una represa del agua de dicho pueblo con su canal y algunas ruinas pero } \\
\text { útil para dichas tierras de labor }\end{array}$ & 40 pesos \\
\hline $\begin{array}{l}\text { Tres tablones de } \\
\text { tierras }\end{array}$ & $\begin{array}{l}\text { Que han sido de labranza lo rosado y limpio de ellos/// y ten el costo y } \\
\text { utilidad de haberse rozado y desmontado los tablones de tierras de pan } \\
\text { llevar respeto del terruño y monte que se cría en lo que está por labrar }\end{array}$ & 52 pesos \\
\hline Árboles frutales & $\begin{array}{l}5 \text { manzanos, } 3 \text { higueras y algunos parrones y árboles de duraznos medio } \\
\text { secos y sin proporción de huerta ni cerco y en desigual distancia por la } \\
\text { orilla de la sequía }\end{array}$ & 35 pesos \\
\hline Corral & $\begin{array}{l}\text { Un corral pequeño con sus sepas y trancas para encierro de ganados de } \\
\text { maderas del porte de barason y algunas más delgadas de algarrobo lo más, } \\
\text { y pocas varas de madera de chañar con } 2 \text { cepos de algarrobo escopleados }\end{array}$ & 25 pesos \\
\hline Dos tapiales & De tablas de algarrobo barrotes y clavos & 35 pesos \\
\hline Un horno de coser pan & Antiguo & 6 pesos \\
\hline
\end{tabular}

Fuente: Elaboración propia con datos provenientes de ABNB EC-1688,42. 
"primeramente dos ranchos el uno de pirca de adobes y otro con cerco de paja y una ramada, todo de Diego indio fiscal de dicho pueblo evaluamos en 12 pesos y 2 reales". "otro rancho de María india viuda y asimismo otro rancho y una ramada con más un cerco para reparo de los vientos todo de la misma viuda evaluamos en 18 pesos y 4 reales"

"y ten un rancho largo de Juan indio de 18 // horcones y pirca de barro y una ramada de seis horcones y otros dos ranchos el cómo de seis horcones y otros grande que servía de troja de 9 horcones todo perteneciente al dicho Juan lo evaluamos todo en 59 pesos y 7 reales"

En las descripciones vemos que cada indio (cabeza de familia) podía tener varios ranchos, buhíos y ramadas. El documento no aclara la diferencia entre estas construcciones, pero deja entrever que los ranchos son los espacios de vivienda, que en el caso de Juan también podían ser usados de troja, mientras que las ramadas parecieran ser cobertizos hechos de ramas de árboles para dar sombra. El término "buhio o bohio" es importado de las Antillas y refiere a las chozas redondas de los taínos con las que se encontraron Colón y los primeros conquistadores, pero no fue posible determinar qué significaba en este contexto.

El valor que le asignan a las viviendas quemadas oscila entre los cinco pesos y dos reales y cincuenta y nueve pesos y siete reales, según la cantidad de espacios dañados (a veces es solo un rancho, pero otras son varios ranchos que le pertenecen a la misma persona, con sus ramadas y buhíos), y su tamaño (expresado en la cantidad de horcones, que eran las maderas verticales que sostenían los techos). El rancho más grande es el de Juan con 18 horcones y le sigue el de Miguel con 13, y los más pequeños son de dos y tres. La mayoría de los ranchos eran de "pirca de barro" y poseían un cerco de paja "para reparo de los vientos" 10 .

En el expediente también figuran los reclamos de varios miembros de la encomienda, quienes al haber sido expulsados del pueblo "con apresuración y violencia" perdieron parte de sus ganados, por los cuales demandan una compensación monetaria. Gracias a este documento sabemos que los indios poseían distintos tipos de ganado en Guaco: vacas, ovejas, cabras y caballos (en el pueblo también había bueyes, pero se aclara que son del encomendero ${ }^{11}$ ), que tenían contabilizados y con señal propia. Los reclamos siguieron este formato:

"Cristóbal indio dijo que por la mudanza de sitio y causa de salir lanzados ha perdido cuatro cabras, con cinco cabritos, cinco ovejas, una vaca con su ternera y una yegua mansa por tirar dichos ganados a su querencia y no poderlos sujetar" (ABNB EC-1688,42 Fol. 29 r.).

Son frecuentes los adjetivos calificativos al describir los animales, ya que esto influía en el precio: "caballo oscuro muy corredor", yeguas de caballería o cerreras, vacas lecheras o cerreras, mansas, flacas, entre otros. Como solamente mencionan aquellos especímenes que perdieron en los traslados, es imposible estimar cuántas cabezas de ganado poseía cada indio.

Este es un sesgo que atraviesa toda la fuente: como se mencionó, solo se nombran los espacios que se modificaron durante el año que los indígenas residieron en Catamarca. Asimismo, hay que considerar que se visibilizan aquellos lugares y elementos que los tasadores consideran que tienen un valor monetario. Con certeza afirmo que hay otros espacios dentro de Guaco que esta fuente no menciona: el resto de los ranchos y asentamientos de vivienda, las tierras de cultivo, tal vez un cementerio y una plaza como se esperaba de un pueblo de indios. Por ejemplo, por otra fuente sé que el encomendero Bazán de Pedraza tenía en Guaco una despensa con llave donde conservaba el maíz de la chacra de comunidad. Cuando se iba de la ciudad, el cacique Gerónimo Pibala guardaba la llave y administraba los granos (AHPC, Esc. 2, Leg. 5, Exp. 11, Fol. 223 r.).

\section{Reflexiones finales}

Esta reconstrucción material muestra que en el pueblo coexistían espacios con distintas funciones: espacios domésticos como los ranchos, los aposentos de vivienda, la cocina; espacios vinculados a lo productivo como los corrales y caballerizas, las tierras de cultivo, la chacra de comunidad ${ }^{12}$ y los árboles frutales y espacios dedicados al culto religioso, como la capilla con sus ornamentos e imágenes. Seguramente también había lugares de sociabilidad como los patios y espacios comunes entre los ranchos. Esta separación de los espacios 
y tareas en la práctica debió ser más fluida, superponiéndose las distintas funciones. Por ejemplo, es probable que en los espacios domésticos se hayan realizado actividades productivas como el hilado y tejido que el encomendero le exigía a las indias, como sugiere Conti para las encomiendas catamarqueñas (2019: 103).

Al comparar el pueblo de Guaco con la normativa alfariana noto que varias ordenanzas se cumplen. Veamos. La número ocho procuraba que cerca de las reducciones hubiera una fuente de agua. Aunque el valle de Sanagasta es árido y los indígenas elevan quejas por falta de agua ${ }^{13}$, construyeron un sistema de acequias que les permitió maximizar el uso de este recurso escaso. La ordenanza $\mathrm{N}^{\circ} 20$ indica que tiene que haber una capilla con puerta y llave, lo que se cumple a pie de letra.

La $\mathrm{N}^{\circ} 26$ establece que el encomendero no puede tener casa ni propiedades a su nombre en el pueblo, pero sí otras construcciones como un depósito con llave, el que está presente en Guaco. La ordenanza $\mathrm{N}^{\circ} 27$ prohíbe los obrajes o viñas del encomendero dentro del pueblo, diciendo que solo puede tener chacras de comida, árboles frutales y ganado. Aparte de bueyes, que Bazán de Pedraza prestaba para el cultivo de las chacras de comunidad e individuales, el expediente no menciona otras instalaciones o bienes del encomendero. No obstante, sabemos que para 1693 el encomendero instaló en Guaco un mayordomo, sobrino suyo, que vivía allí con su madre y que apremiaba a los indios en la recolección de tributos (Boixadós y Zanolli 2003: 159). Además, recordemos que el documento analizado fue producido por parientes suyos, quienes pudieron omitir toda actividad que infringiera la normativa.

El cumplimiento de las ordenanzas que regulan la distancia del pueblo de establecimientos españoles no se puede verificar, ya que no poseo datos de los alrededores de Guaco. Respecto de que las reducciones fueran hechas en tierras de los indios, como vimos este no fue el caso, al ser los malfines y andalgalás llevados de sus territorios "antiguos" en el oeste catamarqueño hacia La Rioja. Otro elemento que parece escapar a la normativa es el ordenamiento del pueblo en "damero", ya que no hay referencias explícitas de que hubiera un trazado urbano cuadriculado. Por el contrario, la descripción sugiere un asentamiento rural disperso. Si bien esto puede estar vinculado con las características ecológicas de la estancia, también puede responder a ciertos márgenes de maniobra utilizados por los indígenas para determinar la forma en que vivían.

Pese a no haber sido un pueblo de indios en sus inicios, Guaco tiene un acatamiento bastante alto de las normativas, lo que contribuyó al aumento del dominio colonial sobre las poblaciones allí reducidas. Como era esperado, la ubicación nucleada -aunque no permanente ni fija debido a la movilidad de la población- puso a los malfines, andalgalás y "anexos" a mayor disposición del encomendero, facilitando prácticas abusivas como el servicio personal. La presencia posterior del mayordomo dentro del pueblo refuerza la subordinación del sector indígena al hispano (ver García 2020). A su vez, la capilla cumple una función evangelizadora y moralizante, y la posesión de ganado señalizado por parte de los indígenas indica su incorporación al mercado colonial. Todo esto contribuyó al disciplinamiento de los indígenas y a su progresiva incorporación al sistema colonial, especialmente si consideramos su pasado rebelde y alzado.

Sin embargo, es necesario matizar la eficacia del control en Guaco. Como se mencionó, la ausencia del característico trazado en damero muestra límites a la aplicación de la territorialidad hispana. Además, se sabe por la visita de 1693 que solo en contadas ocasiones se celebraban misas en la capilla de Guaco, ya que no tenían un cura fijo. Como consecuencia, la mayoría de los indígenas del pueblo no estaban cristianizados, lo que muestra que el proceso de evangelización no estaba avanzado hacia fines del siglo XVII.

La necesidad del encomendero de instalar un poblero para que los indígenas cumplan con la entrega de productos y trabajen la chacra comunitaria, como los frecuentes golpes y castigos recibidos al no cumplir con lo indicado (García 2020), evidencian una resistencia al dominio. Lo mismo indican los reclamos y peticiones judiciales de un sector de la encomienda, liderados por el mandón Francisco Gualcusa, que buscan abandonar Guaco y asentarse en Andalgalá, Catamarca, alejándose del control de sus encomenderos riojanos (García 2018a).

\section{Agradecimientos}

A las Dras. Laura Quiroga y Ma. Cecilia Castellanos, quienes me invitaron a formar parte de este Dossier, a la Dra. Roxana Boixadós por sus comentarios y a los evaluadores de este artículo. 


\section{Referencias Citadas}

Acuto, $\mathrm{F}$

1999 "Paisaje y dominación. La construcción del espacio social en el Imperio Inka". En Sed Non Satiata. Teoría social en la Arqueología Latinoamericana Contemporánea, editado por A. Zarankin y F. Acuto, pp. 33-75. Editorial del Tridente, Buenos Aires.

Anello, A.

2002 "Familia indígena y sociedad en el Curato de Londres (Catamarca), terminando el siglo XVII". En Los pueblos de indios del Tucumán Colonial: Pervivencia y Desestructuración, editado por J. Farberman, y R. Gil Montero, pp. 101-138. UNQ- UNJu, Bernal.

Boixadós, R.

2002 "Los pueblos de indios de La Rioja colonial. Tierra, trabajo y tributo a fines del siglo XVII". En Los pueblos de indios del Tucumán Colonial: Pervivencia y Desestructuración, editado por J. Farberman, y R. Gil Montero, pp. 15-57. UNQ-UNJu, Bernal.

Boixadós, R. y C. Zanolli

2003 La Visita de Luján de Vargas a las Encomiendas de La Rioja y Jujuy. Estudios Preliminares y fuentes. Universidad Nacional de Quilmes, Buenos Aires.

Castro Olañeta, I.

2006 Transformaciones y Continuidades de Sociedades Indígenas en el Sistema Colonial: el pueblo de indios de Quilino a principios del siglo XVII. Alción Editora, Córdoba.

Castro Olañeta, I.

2013 La numeración de los indios del partido del Río Salado. Santiago del Estero, 1607. Encomiendas y servicio personal. (18 febrero 2014) Corpus [En línea], Vol. 3, Nº 2. URL: http: //journals.openedition.org/corpusarchivos/535. (Consultado el 02/12/2019)

Conti, S.

2019 Los pueblos de indios de Catamarca a través de la visita de Luján de Vargas. Tierra, tributo y trabajo. Tesis de para optar al grado de Licenciado en Historia, Facultad de Filosofía y Letras, UBA, Buenos Aires.

de la Orden de Peracca, G.

2008 Los pueblos de indios en Catamarca Colonial. Universidad Nacional de Catamarca, Catamarca.

de la Orden de Peracca, G.

2011 De caciques y alcaldes en Catamarca colonial. Estudio preliminar. Actas de las XIII Jornadas Interescuelas, Editorial Científica Universitaria, Catamarca.

Farberman, J.

2008 "Santiago del Estero y sus pueblos de indios. De las ordenanzas de Alfaro (1612) a las guerras de independencia". Andes, 19: 225-250.

Farberman, J. y R. Boixadós

2006 "Sociedades indígenas y encomienda en el Tucumán colonial. Un análisis comparado de la visita de Luján de Vargas". Revista de Indias, 66 (238): 601-628.

Farberman, J. y R. Boixadós

2009-2010 "Una cartografía del cambio en los pueblos de indios coloniales del Tucumán. Autoridades étnicas, territorialidad y agregaduría en los siglos XVII al XIX". Revista Histórica, 44: 113-146.

Gade, D.

1991 "Reflexiones sobre el asentamiento andino de la época toledana hasta el presente". En Reproducción y transformación de las sociedades andinas, siglos XVI-XX, editado por $\mathrm{S}$. Yáñez y F. Salomon, pp. 69-90. Ediciones ABYA-YALA, Quito.

García, M.

2018a. "Buscando las voces nativas en la justicia colonial: Las autoridades de malfines y andalgalas y su reproducción comunitaria (La Rioja, 1674-1693)”. Andes, 29 (2): 1-39.

García, M.

2018b. Caciques, mandones y encomenderos litigantes: el pleito por la encomienda y estancia de Guaco, La Rioja, 1674-1693. Tesis de para optar al grado de Licenciada en Ciencias Antropológicas, Facultad de Filosofía y Letras, UBA, Buenos Aires.

García, M.

202 "No consienta que el encomendero nos obligue a servicios personales ni nos maltrate". Violencia y castigos infrajudiciales en un Pueblo de indios riojano, fines del siglo XVI. Memoria Americana. Cuadernos de Etnohistoria, 28 (2): 10-31.

Giudicelli, C.

2018 "Disciplining space, territorializing obedience. The politics of reduction and denaturalization of the diaguitascalchaquíes (17th century)”. Chungará, 50 (1): 133-144.

Levillier, R.

1918 Correspondencia de la ciudad de Buenos Aires con los Reyes de España. Biblioteca del Congreso de la Nación Argentina, Madrid.

Lorandi, A. M.

1988 "El servicio personal como agente de desestructuración en el Tucumán colonial". Revista Andina, 6 (1): 135-173.

Lorandi, A. M. y S. Sosa Miatello

1991 "El precio de la libertad. Desnaturalización y traslado de indios rebeldes en el siglo XVII". Memoria Americana, Cuadernos de Etnohistoria 1: 7-28.

Mumford, J.

2012 Vertical Empire. The General Resettlement of Indians in the Colonial Andes, Duke University Press, North Carolina.

Palomeque, $\mathrm{S}$.

2000 "El mundo indígena. Siglos XVI-XVIII". En Nueva Historia Argentina II, editado por E. Tandeter, pp. 87-144, Editorial Sudamericana, Buenos Aires.

Quiroga, L.

2012 "Las granjerías de la tierra: actores y escenarios del conflicto colonial en el valle de Londres (Gobernación del Tucumán, 1607-1611”. Surandino Monográfico, 2 (2): 1-37.

Sica, G.

2008 "El papel y la memoria. Medios de construcción de los procesos de identificación local en los pueblos de indios de Jujuy. Siglo XVII". Andes, 19: 327-344.

Sica, G.

2009 "Transformaciones y formas de legitimación en la autoridad de los caciques coloniales de Jujuy. Siglo XVI". Memoria Americana 17 (1): 33-59.

Taboada, C. y J. Farberman

2014 "Asentamientos prehispánicos y pueblos de indios coloniales sobre el Río Salado (Santiago del Estero, Argentina): miradas dialogadas entre la arqueología y la historia”. Revista de Arqueología Histórica Argentina y Latinoamericana, 8 (1): 7-43. 
Tell, S. y I. Castro Olañeta

2016 “Los pueblos de indios de Córdoba del Tucumán y el pacto colonial (Siglos XVII a XIX)". Revista del Museo de Antropología, 9 (2): 209-220.

Vázquez, F.

2007 La resignificación de la identidad como estrategia de resistencia frente al dominio colonial. Belén, Catamarca (siglos XVII-XVIII). Actas de las Cuartas Jornadas de Jóvenes Investigadores. Instituto de Investigaciones Gino Germani, Buenos Aires.

Wernke, S.

2013 Negotiated Settlements: Andean Communities and Landscapes under Inka and Spanish Colonialism. University Press of Florida, Gainseville.
Zagalsky, P.

2009 'El concepto de 'comunidad' en su dimensión espacial. Una historización de su semántica en el contexto colonial andino (siglos XVI-XVII)". Revista Andina, 48: 57-90.

\section{Fuentes citadas}

Archivo y Bibliotecas Nacionales de Bolivia (ABNB) -Expedientes Coloniales (EC)- 1688,42 "Doña Catalina del Álamo contra Don Gil Bazán de Pedraza, reclamando unos indios Malfines y Andalgalá".

Archivo Histórico de la Provincia de Córdoba, Escribanía 2, Legajo 5, Expediente 11 "Fray Matias de Bergara con Francisco Balqusa sobre propiedad de la Estancia del Guaco".

\section{Notas}

1 Desde esta perspectiva, las relaciones sociales y el habitar hacen que los espacios se impregnen de significados sociales que comunican sentidos y transmiten mensajes sobre cómo fue la estructura de la sociedad que los produjo y qué acciones y prácticas se realizaban allí (Acuto, 1999).

2 Las ordenanzas del gobernador Abreu, de 1576, todavía no separaban la territorialidad indígena de la española, siendo el pueblo de encomienda el espacio principal de las actividades productivas de los vecinos feudatarios (Castro Olañeta, 2013).

3 En este artículo se utilizará la toponimia Guaco y no Huaco, respetando la ortografía de las fuentes.

4 Para más información sobre cómo se constituyó esta encomienda, ver Quiroga (2012) y García (2018a y 2018b ).

5 Reconstruiré brevemente la historia de estas tierras. Pedro Ramírez de Velasco, vecino encomendero de La Rioja e hijo del fundador de la ciudad y gobernador y capitán general de las provincias del Tucumán y Río de la Plata, Juan Ramírez de Velazco, aduciendo la existencia de tierras vacas en el valle de Sanagasta obtuvo en 1621 merced de las tierras denominadas Papaymangasta y Quillavil. En 1646 vende parte de las tierras a Isidro de Villafañe por el valor de doscientos pesos, haciendo la salvedad que no vendía el potrero Umanchao: "lo que vendo con el nombre dicho [refiere la escritura] que hoy los indios llaman Guaco" (AHPC, Escribanía 2, Leg.4, Exp. 26, Fol.83 a 90).

6 Lamentablemente, la visita está incompleta y en muy malas condiciones de conservación, por lo que no se halló el documento original que da cuenta de este otorgamiento de tierras.

7 Esto es visible en el padrón y desagravio de 1667, donde los indios reclaman el pago de los viajes que su encomendero les debe (ver García 2018b) y en la visita de Luján de Vargas (Boixadós y Zanolli 2003).
8 Recordemos que la merced de encomienda suponía la entrega de las poblaciones indígenas y no la tierra, de ahí el conflicto generado con la muerte del encomendero Villafañe (por un lado estaban las mercedes de tierras y por otro las de la mano de obra en el formato de encomienda).

9 Un dato no menor es que tanto Gordillo como Juan Gregorio son familiares directos del encomendero Bazán de Pedraza, por lo que su actuación en el juicio y la descripción que realizan de Guaco puede ser sesgada o tendenciosa, tratando de favorecer los intereses de su pariente.

10 Otro aspecto que me llama la atención de esta descripción es que a varios de los individuos cuyas casas fueron destruidas o perdieron ganado se les agrega el adjetivo de "indio". Esto hace preguntarme si dentro del pueblo vivían personas que no eran consideradas indígenas y que tal vez estaban por fuera de la encomienda. Por ahora no tengo más datos para afirmar esto.

11 En 1682 el encomendero Bazán de Pedraza tenía ocho bueyes en Guaco, los que araban las sementeras de comunidad y las propias de los indígenas (AHPC, Esc. 2, Leg. 5, Exp. $11)$.

12 En la visita del oidor Luján de Vargas se consigna que los indios de Guaco no pagaban tasa ni tributo en plata, sino que se hacía el pago al encomendero de la chacra de comunidad. Bazán de Pedraza les proporcionaba las semillas y los bueyes y una vez finalizada la sementera se sacaba el diezmo y de lo que restaba se dividía la mitad para el encomendero y -en teoría- la otra mitad para ellos (Boixadós y Zanolli 2003: 159, García 2020).

13 Este es el principal motivo por el que algunos miembros de la encomienda pleiteaban por ser reducidos en Andalgalá: argumentaban que por la falta de agua y el clima seco no podían cultivar y vivían enfermos y disgustados (García 2018a). 